\title{
"Tuberculosis": A Surprise Guest in Carcinoma of Pinna
}

\author{
Rajeshwary Aroor ${ }^{1} \quad$ Vadisha Srinivas Bhat $^{1} \quad$ Remya Koikkara $^{1} \quad$ Razna Abdulrahim ${ }^{1}$ \\ Vinay Kumar J. Rajendra ${ }^{2}$ Kishan Prasad H. Laxminarayana ${ }^{3}$ \\ ${ }^{1}$ Departmentof Otorhinolaryngology (ENT), K.S. Hegde Medical \\ Academy, NITTE (deemed to be University), Deralakatte, \\ Mangaluru, Karnataka, India \\ 2Departmentof Surgical Oncology, K.S. Hegde Medical Academy, \\ NITTE (deemed to be University), Deralakatte, Mangaluru, \\ Karnataka, India \\ ${ }^{3}$ Departmentof Pathology, K.S. Hegde Medical Academy, NITTE \\ (deemed to be University), Deralakatte, Mangaluru, Karnataka, \\ India \\ Health Allied Sci NU 2022;12:76-78.

\begin{abstract}
Address for correspondence Vadisha Srinivas Bhat, MS, DNB (ENT), Department of Otorhinolaryngology (ENT), K.S. Hegde Medical Academy, NITTE (Deemed to be University), Deralakatte, Mangaluru 575018, Karnataka, India (e-mail: bvadish@yahoo.co.in).
\end{abstract}

\begin{abstract}
Keywords

- tuberculosis

- squamous cell carcinoma

- pinna

- cervical lymph node

- antituberculosis treatment

Tuberculosis is a common health care problem worldwide, though the incidence has come down in recent years due to various health care programs targeting tuberculosis and improved living conditions. Cervical lymph nodes are among the common sites for extrapulmonary tuberculosis. They usually present with painless enlargement of cervical lymph nodes with or without constitutional symptoms. Tuberculosis rarely coexists with malignancy in the geographical area where the prevalence of tuberculosis is high. The disease needs to be treated with antituberculosis treatment as per standard guidelines and the primary treatment of malignancy. We report a case of an adult male presented with a lesion on the pinna, which was diagnosed as squamous cell carcinoma of the pinna on biopsy; he was later found to have coexistent tuberculosis after undergoing surgery for carcinoma.
\end{abstract}

\section{Introduction}

Tuberculosis (TB) is a common health problem worldwide, especially in countries like India. The disease affects the lungs commonly but can affect any other organ. Cervical lymph nodes are the common site of extrapulmonary TB. They usually present as painless mass, often at the posterior cervical triangle or upper jugular group of lymph nodes. Diagnosis of TB of cervical lymph nodes is made by fine-needle aspiration cytology (FNAC); occasionally, excision biopsy of the node may be required.

The coexistence of TB with squamous cell carcinoma is not very common. There are reports of TB of cervical lymph nodes, which were resistant to conventional antituberculosis

published online May 18, 2021
DOI https://doi.org/

$10.1055 / \mathrm{s}-0041-1726680$ ISSN 2582-4287 treatment, which on further evaluation lead to the diagnosis of carcinoma. ${ }^{1}$ However, the disease may be diagnosed only during histopathological examination when surgery is performed in a diagnosed case of carcinoma. We report one such case, where TB was an incidental diagnosis following surgery for carcinoma.

\section{Case Report}

A 60-year-old man presented with a painless swelling over the left pinna of 2 months duration, which later ulcerated. Meanwhile, he developed a swelling behind the pinna and swelling over the left side of the upper neck in the last month.
(C) 2021. Nitte (Deemed to be University).

Nitte University. This is an open access article published by Thieme under the terms of the Creative Commons Attribution-NonDerivative-NonCommercial-License, permitting copying and reproduction so long as the original work is given appropriate credit. Contents may not be used for commercial purposes, or adapted, remixed, transformed or built upon. (https://creativecommons.org/licenses/by-nc-nd/4.0/). Thieme Medical and Scientific Publishers Pvt. Ltd. A-12, 2nd Floor, Sector 2, Noida-201301 UP, India 
He was in a good general health state. An ulceroproliferative lesion was noted over the left pinna's helix, while the lower part of the helix and the lobule were dark in color ( - Fig. 1). There was a hard mass measuring $3 \mathrm{~cm} \times 4 \mathrm{~cm}$ noted in the left postauricular region, with a discharging sinus on the top of the swelling. A firm mobile lymph node measuring $\sim 3 \mathrm{~cm}$ $\times 3 \mathrm{~cm}$ was noted in the left level 2 region. Two smaller lymph nodes were palpable adjacent to this lymph node. No other abnormalities were noted. The chest radiograph showed healthy lung fields. All hematological parameters were within normal limits. With a clinical diagnosis of malignancy of the pinna, a punch biopsy of the lesion was performed. Histopathology was suggestive of well-differentiated squamous cell carcinoma. A computed tomography scan of the neck showed an enhancing thickening of the left external ear, extending to the external auditory canal, with enlarged left level 1b, 2, 3, and 5 lymph nodes.

The patient underwent wide excision of the lesion on the pinna with modified radical neck dissection. ( - Figs. 2 and $\mathbf{3}$ ). Histopathology showed features of squamous cell carcinoma in the pinna with secondaries in the neck nodes. In addition to squamous cell carcinoma, the resected pinna and 24 out of 41 of the lymph nodes showed granuloma consisting of epitheloid cells and Langhans giant cells, suggestive of granulomatous condition, most likely to be TB ( - Figs. 4 and $\mathbf{5}$ ).

Sputum examination did not show acid-fast bacilli. The patient was treated initially with antituberculosis treatment.

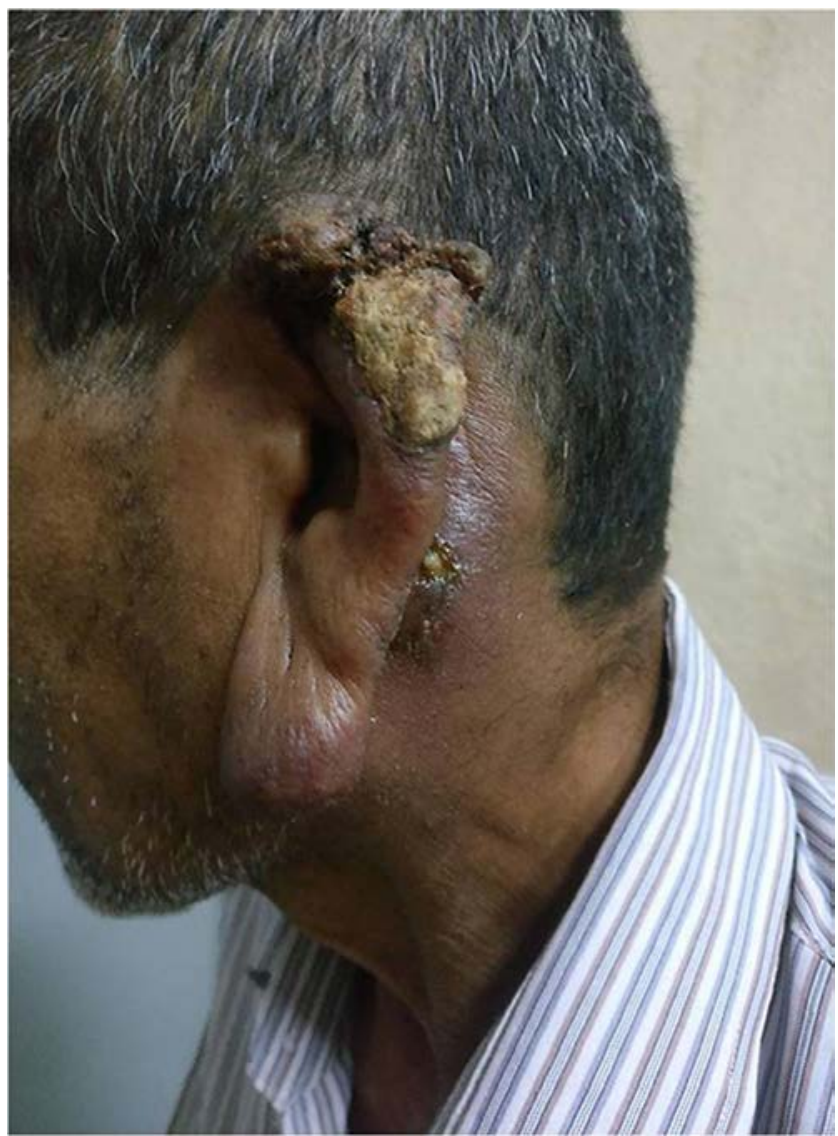

Fig. 1 Clinical photograph showing lesion over the pinna and postauricular region.

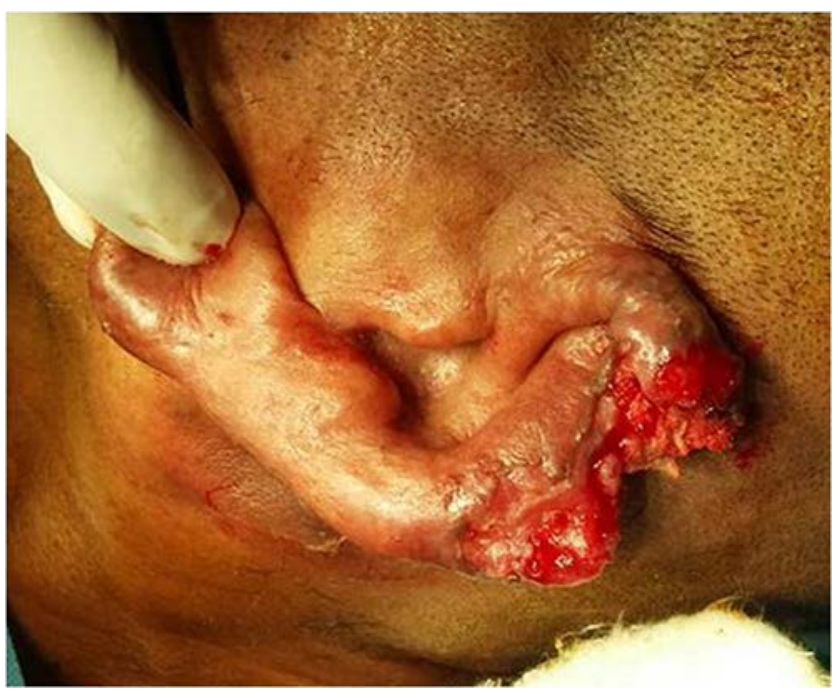

Fig. 2 Wide excision of the tumor of the pinna.

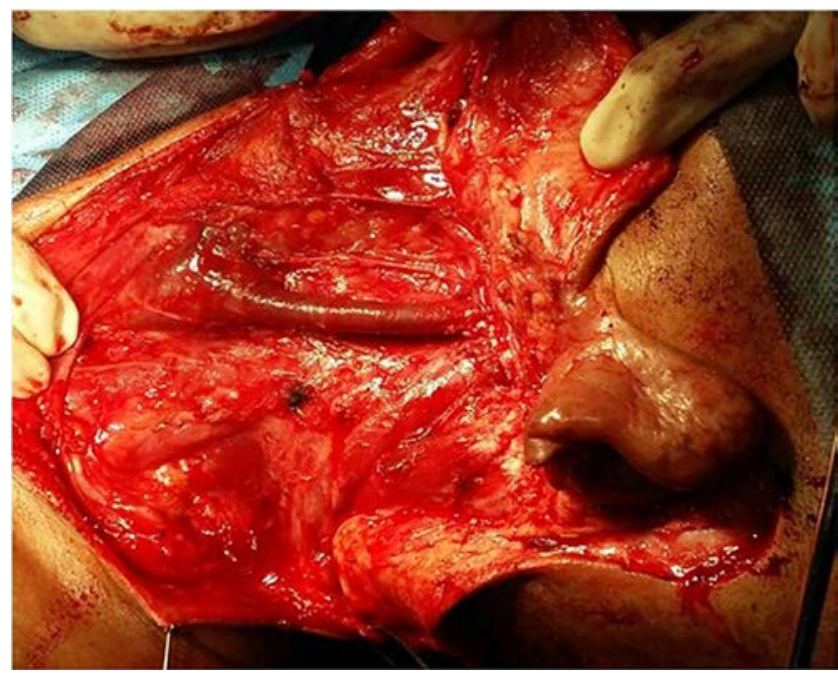

Fig. 3 Modified radical neck dissection.

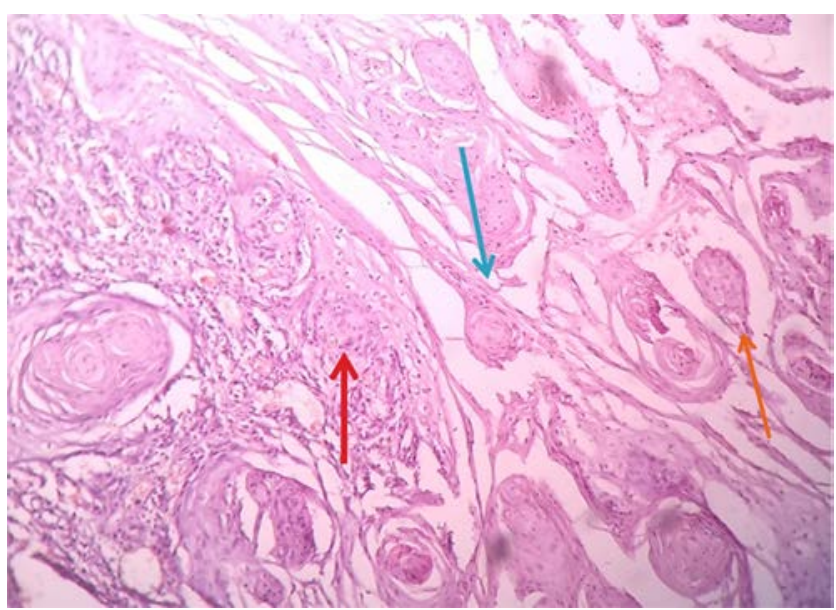

Fig. 4 Histopathology (H\&E, 10x) showing features of squamous cell carcinoma and tuberculosis (red arrow-Langhans giant cells; bluekeratin pearls; orange-tumor cells). 


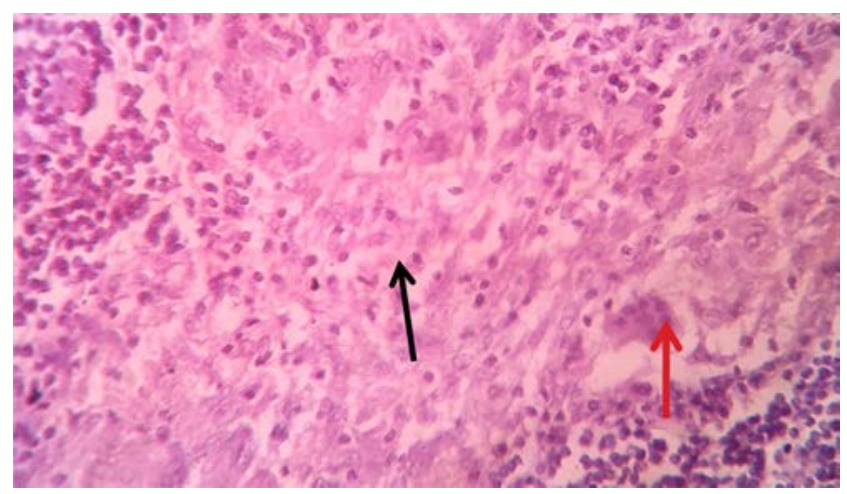

Fig. 5 Histopathology (H\&E, 10×) showing tumor cells (orange) and epithelioid cells (black).

After 2 months of intensive phase with four drugs-ethambutol, isoniazid, rifampicin, and ryrazinamide-he was subjected to adjuvant external beam radiotherapy of 60 gray along with continuation phase of antituberculosis therapy with isoniazid and rifampicin for 4 months. The patient responded well to the treatment, and he is free of both diseases in 18 months follow-up period.

\section{Discussion}

Because of the improved living environment, bacille Calmette-Guérin (BCG) vaccination, and effective antituberculosis drugs, the incidence of TB has reduced in recent years. The disease primarily affects the lungs, which is a well-known fact. Even in countries where the prevalence of TB is high, cutaneous TB is uncommon. Cutaneous TB is less common than other forms of TB but accounts for 1.5\% of all extrapulmonary TB cases. The source of mycobacterial infection and the host's immune status determines the clinical manifestations seen in cutaneous TB. ${ }^{2}$ Different forms of cutaneous TB are lupus vulgaris, scrofuloderma, TB verrucosa cutis, lichen scrofulosorum, erythema induratum, papulonecrotictuberculid. ${ }^{3}$ Cutaneous TB may remain undiagnosed for an extended period because of the lack of a typical form of presentation or the delay in seeking medical advice. In general, cutaneous ТВ is expected in the head and neck region. ${ }^{4}$ Biopsy and histopathological examination are the preferred investigation for diagnosing the disease. The culture positivity is low, ranging from $0 \%$ to $57 \%{ }^{2}$ Histologically, the lesions show caseating granuloma, but occasionally noncaseating consisting of Langhans giant cells, epithelioid cells, and infiltration of chronic inflammatory cells. In the absence of typical histological features, polymerase chain reaction (PCR) helps identify mycobacterium tuberculosis DNA in the tissue when there is a clinical suspicion of TB. ${ }^{5}$

The coexistence of TB and metastatic carcinoma in lymph nodes is rare, even in countries where the disease is common. Cutaneous malignancies of the head and neck are usually basal cell carcinoma, which comprises $60 \%$, while $50 \%$ of pinna malignancies are squamous cell carcinoma. Squamous cell carcinoma may arise from an active or treated case of cutaneous TB, called lupus carcinoma. ${ }^{6}$ Gheriani et al reported a case of squamous cell carcinoma of pinna with tubercular lymphadenitis in the neck along with secondaries in the neck. ${ }^{1}$ Caroppo et al reported a case where squamous cell carcinoma of the buccal mucosa presented with tubercular lymphadenitis along with secondaries in the neck. ${ }^{7}$ Mezri et al reported an incident with simultaneous TB and undifferentiated metastatic carcinoma of the nasopharynx, where the diagnostic dilemma is higher. ${ }^{8}$ In our case, there were squamous cell carcinoma and TB in both the primary lesion and the cervical lymph nodes. There is a possibility that the disease is carried to the lymph nodes from the primary site, along with metastasis. However, as both the primary and the metastatic lymph nodes had both TB and carcinoma, the staging of carcinoma would not have altered, and the treatment would remain the same. We conclude that in countries where the disease is endemic, careful histological examination of all the resected lymph nodes, in case of head and neck malignancy, should look for the coexistence of TB, particularly in elderly patients where there is a chance of cancer-induced immune suppression.

\section{Conflict of interest}

None declared.

\section{References}

1 Gheriani H, Hafidh M, Smyth D, O’Dwyer T. Coexistent cervical tuberculosis and metastatic squamous cell carcinoma in a single lymph node group: a diagnostic dilemma. Ear Nose Throat J 2006;85(6):397-399

2 Kaimal S, Aithal V, Kumaran MS, Abraham A. Cutaneous tuberculosis of the pinna: a report of two cases. Int J Dermatol 2013;52(6):714-717

3 Tappeiner G, Wolff K, Tuberculosis and other mycobacterial infections. In: Freedberg IM, Eisen AZ, Wolff K, Austen KF, Goldsmith LA, Katz SI, eds. Fitzpatrick's Dermatology in General Medicine. Vol 2. New York, NY: McGraw Hill; 2003:1933-1950

4 Ramesh V, Misra RS, Jain RK. Secondary tuberculosis of the skin. Clinical features and problems in laboratory diagnosis. Int J Dermatol 1987;26(9):578-581

5 Padmavathy L, Rao L, Veliath A. Utility of polymerase chain reaction as a diagnostic tool in cutaneous tuberculosis. Indian J Dermatol Venereol Leprol 2003;69(3):214-216

6 Bhat VS, Bhandary SK, Shenoy MS, Bk SC, Bs G. A rare case of lupus carcinoma of external nose. Indian J Surg Oncol 2011;2(3):215-217

7 Caroppo D, Russo D, Merolla F, et al. A rare case of coexistence of metastasis from head and neck squamous cell carcinoma and tuberculosis within a neck lymph node. Diagn Pathol 2015;10:197

8 Mezri S, Sayhi S, Ben Amira M, et al. Coexistence of tuberculosis and metastatic undifferentiated carcinoma of nasopharynx in cervical lymph node. Otolaryngol Open J 2019;5(2):26-28 